and worse with greater incendiary communication. Other family factors having a significant influence for at least one group were mutuality, family strains, and condition management ability. Findings contribute to our understanding of the underlying processes associated with age-based differences in family functioning in families of children with DS. Nurses need to recognize the importance of family factors and understand that different family factors may gain importance as the child ages.

\title{
OC42 - What do parents know about fever?
}

\author{
Manuela Pereira (Portugal) ${ }^{1}$; Isabel Bica (Portugal)2; João Duarte \\ (Portugal)2; Margarida Reis Santos (Portugal)³; Ernestina Silva \\ (Portugal) ${ }^{2} ;$ Patrícia Costa (Portugal) ${ }^{4}$
}

${ }^{1}$ ACES Dão Lafões - USF Alves Martins, Viseu; ${ }^{2}$ CI\&DETS - Health School of Viseu
- Polytechnic Institute of Viseu; ${ }^{3}$ Escola Superior de Enfermagem do Porto; ${ }^{4}$ ACeS
Dão Lafões, USF Terras de Azurara, Mangualde

Theme: Parenting/parenthood.

Keywords: Children, fever, knowledge, parents.

Introduction: Due to lack of information, the fever in the child brings anxiety and fear to their parents.

Objectives: To identify parents' knowledge towards the child with fever and the sources of information they have used.

Methods: Cross-sectional, descriptive-correlational study. Convenience not probabilistic sample of 360 parents with children in child health surveillance consultation, in central Portugal. Data collection was performed by a questionnaire about fever in children.

Results: Knowledge of the fever was found to be weak among parents aged $\geq 38$ years (36.2\%) with a partner (77.0\%), living in rural areas (69.3\%) and having completed the ninth grade (53.9\%). Parents up to 37 years (68.2\%) with a partner (89.0\%), living in urban area (53.0\%) and having higher education (43.3\%) showed good knowledge. The main sources of information were the doctor (65.8\%) and nurses (50.6\%).

Conclusion: Nurses need to invest in training parents more on this subject.

\section{OC43 - Reproductive decision-making in families of children with Down syndrome}

\author{
Marcia Van Riper (United States of America) ${ }^{1}$ \\ ${ }^{1}$ University of North Carolina at Chapel Hill
}

Theme: Ethical issues: dignity and humanity.

Keywords: Down syndrome, prenatal, ethical issues, genetic testing, family.

Reproductive decision-making generally becomes much more complex in families once they have given birth to a child with a genetic condition. The question of whether or not to have 